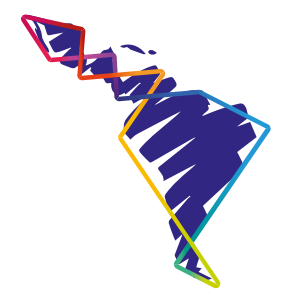

\title{
Venda Sexy: Memorias no oficiales de un centro de detención
}

\section{Venda Sexy: unofficial memories of a detention center}

\author{
Claudia Arellano Hermosilla
}

\begin{abstract}
Resumen
El siguiente artículo reflexiona en torno a las memorias y relatos de mujeres que fueron sobrevivientes del Centro de Detención y Tortura la Venda Sexy, de la Dirección de Inteligencia Nacional (DINA), durante la dictadura militar en Chile. Este recinto en particular agudizó la represión, volcada a la violencia política sexual. Dentro de estas condiciones, en extremo represivas, existieron instancias de resistencia y sororidad entre las mujeres, lo que les permitió doblegar esa herida histórica, hacia un proceso de agenciamiento, trasladada a la lucha feminista actual.
\end{abstract}

Palabras clave: Memoria, tortura, prisión política, género.

\section{Summary}

The following article reflects on the memories and stories of women who were survivors of the Centro de Detención y Tortura la Venda Sexy (Venda Sexy Detention and Torture Center), of the Directorate of National Intelligence (DINA), during the military dictatorship in Chile. This precinct, in particular, exacerbated the repression, inclined towards sexual political violence. Within these extremely repressive conditions there existed instances of resistance and sorority among women, which allowed them to bend that historical wound, towards an assemblage process, which has translocated to the current feminist struggle.

Keywords: Memory; Torture; Political prison; Gender.

1 Antropóloga, Magister en Estudios Latinoamericanos, Universidad Paris III Sorbonne Nouvelle y Doctora en Estudios de Género de la Universidad París VIII Saint Denis, actualmente se desempeña como docente e investigadora en la Escuela de Antropología de la Universidad Academia de Humanismo Cristiano en Santiago de Chile. 


\section{Introducción}

En Chile, durante el periodo de la dictadura militar, uno de los pasos en la política represiva de la dictadura fue la creación de la DINA que, en conjunto con otros organismos de inteligencia, violaron los derechos humanos ${ }^{2}$; su principal función fue la administración del terror a quienes fueran simpatizantes de una ideología política diferente a la del Estado, es decir, militantes, simpatizantes, colaboradores, dirigentes, familiares, etc., pasaron por inenarrables sesiones de tormentos en las temidas casas de tortura entre 1974 y 1977 (Guzmán, 2014), en las cuales se practicó violencia física, psicológica y sexual a las personas detenidas. Esta violencia política no terminó cuando desapareció la amenaza represiva, sino que se instauró en la malla social. De esta forma, se logró instalar el control social, suprimiendo libertades civiles y políticas por medio del reinado del terror, el cual ha operado en la invisibilización del conjunto de los derechos humanos. (Taramasco, 2003).

Este artículo se enmarca dentro del estudio del Núcleo Temático de Investigación GIME (Género, Imagen y Memoria) desarrollado entre el año 2016 y 2017 con un grupo de estudiantes ${ }^{3}$ de la Escuela de Antropología de la Universidad Academia de Humanismo Cristiano, quienes trabajamos en el rescate de la memoria histórica política sexual, con sobrevivientes ${ }^{4}$ de la "Venda Sexy", que fue un centro de detención y torturas de la Dirección de Inteligencia Nacional (DINA), durante la dictadura militar, y que funcionó desde fines del año 1974, hasta mediados del 1975. Esta casa de tortura, también era llamada "La Discotheque", debido a que los agentes de Pinochet tocaban música estridente continuamente (Chornik, 2019). Como nos relata Alejandra: "sentíamos los perros que ladraban afuera, nos dimos cuenta de que la casa de la venda sexy estaba al lado de la vereda, de la calle ... nuestros gritos se escuchaban en la casa de al lado, por eso ponían la música tan fuerte" (Entrevista Alejandra Holszaphel, 2017).

En todos los centros de detención y tortura se aplicó una brutal crueldad, en este recinto en particular se agudizó la violencia sexual, tanto para mujeres y comp para hombres. Dentro de estas condiciones, en extremo represivas, también existieron

2 "La noción de los Derechos humanos se corresponde con la afirmación de la dignidad de la persona frente al Estado. El poder público debe ejercerse al servicio del ser humano: no puede ser empleado lícitamente para ofender atributos inherentes a la persona y debe ser vehículo para que ella pueda vivir en sociedad en condiciones cónsonas con la misma dignidad que le es consustancial” (Nikken, 1994, p. 23)

3 Camila Varas, Gittel Villablanca, Elías Quintana, Constanza Sepúlveda, Isidora Ruiz, Paloma Vargas, Luis Lara, Yasna Herrera.

4 Nuestros entrevistados fueron: Alejandra Holzaphel, Beatriz Batastew, Nora Guillén, Boris Chornik, Elías Padilla y Gonzalo Ruiz, todos sobrevivientes de la casa de tortura Venda Sexy.

5 La venda sexy fue una casa de tortura ubicada en calle Irán 3037, esquina los Plátanos en la comuna de Macul. Funcionó desde finales de 1974 y hasta mediados de 1975. 
instancias de resistencia. Muchas mujeres recuerdan una solidaridad entre ellas, lo cual les permitió volcar esa herida histórica hacia la lucha política feminista actual.

Una de las preguntas iniciales para abordar nuestra investigación fue: ¿De qué manera hombres y mujeres ${ }^{6}$ resignifican los procesos de detención y tortura acontecidos en periodos de Dictadura Militar?

En este artículo reflexionaremos en torno a dos momentos de la "memoria narrativa", por quienes sobrevivieron a la tortura. Un primer momento, esta memoria narrativa actuaría desde una "condición traumática", como nos recuerda Edkins,

Lo que denominamos trauma, tiene lugar cuando los mismos poderes que creemos que van a protegernos y darnos seguridad se convierten en nuestros verdugos. Si ese orden nos traiciona de alguna forma, podemos sobrevivir en el sentido de continuar como seres físicos, pero el significado de nuestra existencia cambia. (Edkins, 2003, citado en Arellano, 2017, p. 18)

De este modo, los seres humanos podemos resignificar nuestros recuerdos y poder generar agenciamiento. Es así como Pierre Janet (2006) nos ayuda en la distinción entre lo que él entiende como memoria habitual y la memoria narrativa,

La memoria narrativa, esta es aquella que mediante evaluaciones subjetivas permite darle sentido a la experiencia cotidiana, en la medida en que construye estructuras mentales paradigmáticas, que sirven para acoger experiencias habituales. La memoria narrativa, en cambio, exige un trabajo de conciencia y, por lo mismo, es un acto social en la medida que su construcción ocurre en un contexto de convenciones y acuerdos sociales preexistentes. De este modo, las experiencias familiares y cotidianas se integran de manera más o menos automática, no así aquéllas extrañas y amenazadoras, las cuales lo hacen con mayor dificultad o se resisten de ser asimiladas. (Janet, 2006, citado en Arellano, 2017, p. 18)

Activar los recuerdos constituye una práctica política llevada a cabo por todos los sujetos sociales, en distintos grados y formas, y es aquí donde nos sumergiremos, en esa memoria traumática, que emana de una experiencia ajena y violenta, pero que en el proceso de contar y verbalizar la narrativa personal y la narrativa histórica van dejando de lado esa memoria traumática no contada o contada parcialmente. Sabemos que activar los recuerdos es "enfrentar el pasado" y muchas veces este

6 De las 3400 mujeres que declararon en la Comisión Valech, la gran mayoría admitió haber sido víctima de algún tipo de violencia sexual. Si bien 316 dijeron haber sido violadas, se estima que esa cantidad es mucho mayor, ya que "la violación sexual es para muchas mujeres un hecho del cual les cuesta hablar y muchas veces prefieren no hacerlo", consigna el informe. 
retorno representa un trance demasiado doloroso, y ante ello los individuos optan por evadirlo o posponerlo indefinidamente, ya que no logran encontrar un canal simbólico o una forma expresiva de comunicación para expresarlo (Arellano, 2017).

En el desarrollo de la investigación, nos dimos cuenta de que el trauma provocado por las torturas y violaciones a los derechos humanos, en este grupo específico de mujeres que pasaron por la Venda Sexy, tuvo todo un proceso de resignificación, que las llevó a volcar ese (trauma) hacia la lucha política, es decir, primero a partir de un trabajo interior de aceptación de la tortura (no de perdón), luego de la verbalización de sus vivencias (hablar, contar) y así volver a crear movimientos colectivos de lucha para reivindicar políticas en DDHH, casas de memoria y luchar por el castigo a los sujetos culpables.

\section{Las políticas de la memoria}

Nuestras memorias son personales, pero es al compartirlas, como señala Halbwachs, que estas son autorizadas y ofrecen, de este modo, el salvoconducto que nos une colectivamente. En tal contexto, las convenciones discursivas constituyen, al mismo tiempo, el marco más elemental y estable para las memorias colectivas (Halbwachs, 2011). Con esto estamos diciendo que se trata de recuperar "el conflicto como estado moral de la diferencia”, que, según Nelly Richard, consiste, al menos en la escena crítica chilena, en perturbar la yerma reconciliación de la homogeneización y de armonía prefabricada, en donde las agencias de control ... han institucionalizado ciertos mecanismos de la memoria, mientras al mismo tiempo se instauran técnicas de olvido (Richard, 2001). Por su parte Gabriel Salazar agrega que "los recuerdos privados no han encontrado una reproducción correspondiente y exacta en el plano de la memoria pública [...] todavía estamos exigiendo que la memoria pública coincida con la privada" (Salazar, 2001, p. 65).

En el contexto chileno, la manera de darle valor a Mnemosine está siendo expuesta desde distintas particularidades políticas biográficas, que se han ido rearticulando y, así, proponiendo modos para vencer la política amnésica impulsada por los agentes políticos interesados en enterrar el pasado. De esta forma, la relectura del pasado hace del futuro un terreno cierto, donde el pasado adopta un poder agencial.

En la actualidad, algunas personas creen que esta represión y los abusos son fenómenos del pasado dictatorial. El pasado es, sin embargo, una parte central del presente. El conflicto social y político sobre cómo procesar el pasado represivo reciente permanece y a menudo se agudiza, sobre todo en quienes fueron víctimas de las torturas y de violaciones a los derechos humanos en nuestro país. A pesar 
de que en casi toda Latinoamérica se han promulgado leyes en defensa de los derechos humanos, aún quedan pendientes innumerables delitos, como la vigencia del Decreto de Ley de Amnistía o la Justicia Militar y la instalación de derechos internacionales sobre la violencia sexual en los temas de tortura (Jelin, 2002).

Podríamos señalar que las "políticas de la memoria", en un sentido amplio, son un recurso de la sociedad para interpretar y apropiarse de su pasado en un esfuerzo sostenido por moldear su futuro. Barahona de Brito plantea que la memoria representa una lucha de poder sobre quién decide el futuro. Qué y cómo las sociedades eligen recordar y olvidar determina, en gran medida, sus opciones futuras (Barahona de Brito, 2001). Es así como el control sobre las narrativas del pasado significa vigilar la construcción de narrativas para imaginar el futuro. Y por esto, el conflicto de la memoria en la sociedad chilena actual constituye una problemática política, en donde tanto las memorias individuales como las oficiales se encuentran en continua lucha para llegar a ser parte de la memoria social.

Desde esta óptica, las posibilidades de constituir comunidad descansan, por tanto, en memorias compartidas, autorizadas grupalmente, lo que permite pensar y pensarse en armonía y concordancia con otros seres. Cuando se rompen los lazos comunicantes que llevan a cotejar dichas memorias y pactar "recuerdos" y "acuerdos", las memorias de unos y otros se disocian, entonces, la pugna explícita de colectividades o grupos enfrentados a modelos socioculturales distintos se traslada al plano simbólico de afrontar su propio resumen de la mnemosine, y es así como accedemos a las políticas de la memoria, las que están en constante ejercicio, pero exacerban su naturaleza conflictiva cuando a las formas tradicionales (políticas de género, de clase, étnicas, regionales, generacionales, religiosas), se le suman los conflictos político-históricos (Pino-Ojeda, 2011).

Las reflexiones de Hannah Arendt nos subrayan sobre la importancia histórica de la memoria. Arendt reflexiona sobre cómo las memorias colectivas fueron cohersionadas por "el terror que es la esencia de la dominación totalitaria" (Arendt, 2006, p.\#). De esta forma se unen la memoria del terror, el miedo y la falta de capacidad para reaccionar. En el caso chileno, las políticas neoliberales han ejercido este papel, sirviéndose de los miedos dejados por la dictadura, ya que el terror al disenso ya no surge del miedo a la represión autoritaria, sino de cualquier acción que se interprete como peligro para las políticas de reconciliación y fortalecimiento de las políticas del no conflicto, de esta forma se impone "el acuerdo total" (Pino-Ojeda, 2011). El dispositivo neoliberal ha eliminado el terror expresado en la violencia sicológica o física explícita, directa, para reservarlo al placer de consumir, que sirve de alivio ante la pérdida de la facultad de disentir, de rebelarse, construyendo sujetos alienados, "animales de rebaño", como diría Nietzsche. Hannah Arendt 
(2006) le llamó la "banda de hierro", la cual comprime de tal modo el cuerpo social, destruyendo la pluralidad al imponer el uno, lo que lleva al aislamiento y a la soledad en donde son sumidos los individuos una vez que los canales comunicantes han sido borrados.

En el caso chileno, la memoria del terror, el miedo y la falta de capacidad para reaccionar, producto de la dictadura, habría dado lugar al surgimiento de un trauma social, el cual respondió mediante un absolutismo ideológico asentado en lo económico "la utopía neoliberal", la cual ya no necesita del Estado para gobernar. En este escenario, el sentimiento de ausencia y de carencia es compensado con la omnipresencia del mercado y la absolutización de lo individual.

\section{Las memorias de la tortura}

Jean Franco (1992), quien ha trabajado con testimonios de sobrevivientes de las dictaduras militares en América Latina, sostiene:

Las consecuencias de dichas experiencias límite fueron distintas para ambos sexos y que esas diferencias se hacen evidentes en los relatos testimoniales de los sobrevivientes. Para la autora, los testimonios escritos por hombres -entre los que destaca el del chileno Hernán Valdés ${ }^{8}$ - revelan una propensión a la feminización de la masculinidad que fue necesaria para sobrevivir a las vejaciones, los golpes y las torturas. En el caso de las mujeres, donde analiza el texto de la argentina Alicia Partnoy (2006), identifica una tendencia a evitar los detalles sobre sus padecimientos; hecho que para Franco se explica porque los métodos represivos fueron distintos para la mayoría de las mujeres, quienes además de los golpes y las torturas sufrieron violaciones sexuales. (Franco, 1992, citada en Daona, 2013, p. 58)

Según Jean Franco -para las mujeres- ofrecer su testimonio significó recuperar un pasado suprimido y, en el proceso, comenzar a recuperar su dignidad humana (Franco, 1992). En este caso, el proceso de "dar voz a las enmudecidas" es parte de la transformación del sentido del pasado, que incluye redefiniciones profundas y reescrituras de la historia. Su función es mucho más que la de enriquecer y complementar las voces dominantes que establecen el marco para la memoria pública.

7 Arendt describe el terror estructural totalitario como una masa compacta y homogénea, atada a la banda de hierro que instala a todo el mundo en el consumo, para actuar de manera refleja y no reflexiva.

8 Tejas verdes. Diario de un campo de concentración en Chile, publicado por vez primera en España en 1974, bajo la dictadura franquista, documento de denuncia de los métodos de represión de la dictadura chilena, descripción minuciosa del entorno carcelario y de sus cancerberos militares, así como de la intimidad emocional de aquellos sometidos, como él, a una situación de extrema ansiedad y horror. 
Las memorias personales de la tortura y la cárcel están fuertemente marcadas por la centralidad del cuerpo. Según Jelin, la posibilidad de incorporarlas al campo de las memorias sociales presenta una paradoja: el acto de la represión violó la privacidad y la intimidad, quebrando la división cultural entre el ámbito público y la experiencia privada. (Jelin, 2001, p. 113)

Superar el vacío traumático creado por la represión implica la posibilidad de elaborar una memoria narrativa de la experiencia, que necesariamente es pública, en el sentido de que debe ser compartida y comunicada a otros y otras:

Al principio una siente mucha vergüenza, no te atreves ni a contar lo que viviste. Pasaron muchos años antes de que yo pudiera enfrentar la situación, lo que viví... cuando yo salí de Chile no podía ni conversar con un hombre, ni cerca, me bajaban pataletas y locuras, tuve que ir al siquiatra y tomar pastillas... fue en el período que vivía en Potsdam-Alemania, fue un tiempo muy difícil...tomaba mucho Valium, entonces Valium cada cuatro horas... lo único que hacía era dormir... Dormía, dormía, abría los ojos y los cerraba, porque no sabía cómo enfrentar lo vivido ... y ahí te dije lo de la vergüenza, porque en el fondo yo no me atrevía a decirle a nadie que me habían violado. (Entrevista a Holszaphel, agosto 2017)

Nuestra entrevistada nos relata que, años más tarde, pudo elaborar esa memoria narrativa de la experiencia:

...y en esas conversas, mientras tejíamos, bordábamos, empezaba la terapia, que fue la mejor terapia más que cualquier siquiatra o psicólogo, después de todo estos años, la mejor terapia fue en tres álamos, porque de repente una dijo a mí me violaron, pucha a mí también y empezamos a darnos cuenta que la historia mía era de todas, entonces cuando tu sociabilizas se te empieza a pasar la angustia, empiezas a revertir la vergüenza. (Entrevista a Holszaphel, agosto 2017)

Con estas palabras, se comienza el proceso de mitigar el trauma doloroso de la tortura que, en el caso de la mayoría de las mujeres que pasaron por Venda Sexy, fue la violación. Aquellas mujeres tuvieron que "arrancar la palabra del útero", que fue un desgarramiento, una hemorragia identitaria9 (Arellano, 2015 , p. 15). Y esto consiste en evidenciar y enfrentar "ese cuerpo" ultrajado, violado, y abrirlo y mostrarlo con subversión, de cara al trauma de las vejaciones de la represión, para que, de esta forma, se pueda generar el reconocimiento de memorias que sean capaces de articular el pasado, no de olvidarlo, sino de

9 Esta "hemorragia identitaria" está asociada a la pérdida o el abandono del "dominio del terror", para de esta forma obtener otra resignificación. 
reescribirlo, otorgándole otras significaciones, que son la matriz sobre la cual se habrá de plasmar el agenciamiento:

Descubrimos que no nos violaban cuando estábamos con la regla. Como había compañeras que tenían heridas de balazo o de distintas cosas, entonces nos organizamos para que nos dejaran trapitos con sangre debajo de la taza del WC, y nosotras nos poníamos esos paños con sangre cuando éramos llevadas a la tortura y a la violación. Un día nos dicen: y a estas weonas que les pasó que están todas con la regla, y ese día no violaron a nadie. Era una forma de protegernos, dentro de esa situación tan vulnerable, porque igual tuvimos capacidad de pensar cómo hacerlo, cómo defendernos ante tanta atrocidad. (Entrevista a Holszaphel, agosto 2017)

Las estrategias que utilizaron las mujeres para protegerse y cuidarse en las casas de tortura se basaron en una sororidad ${ }^{10}$, brindándose apoyo y solidaridad frente a los vejámenes ocurridos. Como bell hooks nos diría "nos unimos para proteger nuestros intereses como mujeres" (hooks, 2017, p. 37). Entre las detenidas, sostuvieron una unión, respeto y amor:

La relación con las compañeras es uno de los recuerdos más lindos... porque cuando llegabas de la sala de tortura, ellas te abrazaban, se armaba un ambiente de amor, de cariño, de fraternidad. Creo que, por esas demostraciones de cariño, en las mujeres que somos sobrevivientes, gestó una cofradía, una fraternidad muy grande de amor entre nosotras, porque eran momentos muy difíciles y uno venía muy jodida (Entrevista a Holszaphel, agosto 2017)

En una ocasión una compañera me dice, vamos al baño juntas, pudimos entrar y entramos a ese baño con una ventana con una claraboya de esas de barcos y una vez en el baño, cerramos el pestillo y ambas nos sacamos la venda y ella me dice su nombre, y yo le digo el mío y nos abrazamos. Y la idea era que quién saliera primero, le avisará a la familia de la otra. Para eso era decir el nombre. Pero ahí ocurrió cómo un milagro, ambas nos habíamos conocido cuando niñas chicas. Ella era Guida Vera Almarza, la mataron después, la hicieron desaparecer. Nos contamos brevemente nuestras actividades y bueno, tuve la ocasión de verla y tener ese encuentro maravilloso con ella, (Entrevista a Nora Guillén, septiembre 2017)

Recuerdo momentos de apoyo, de contención entre nosotras, y también recuerdo momentos dramáticos. Recuerdo de una compañera que le vino un paro respiratorio y eso fue tremendo. Menos mal que una de nuestras compañeras, la María Cristina $\mathrm{Za}$ mora la atendió en ese minuto, después se la llevaron porque ella se estaba muriendo.

10 La sororidad es un término derivado del latín soror que significa hermana. Sororidad es un término utilizado para referirse a la hermandad entre mujeres con respecto a las cuestiones sociales de género. 
También recuerdo de esas situaciones terroríficas cuando la Marta Neira volvió del subterráneo y nos contó que había sido abusada por un perro. Y eso fue tremendo para todas nosotras porque en alguna parte sabíamos que era altamente probable que también nos tocara a nosotras. (Entrevista a Beatriz Bataszew, julio del 2017)

Si bien existió la sororidad entre las mujeres detenidas en los centros de tortura, hay que destacar que también existieron mujeres a cargo de la represión y la tortura, es el caso de Ingrid Olderock ${ }^{11}$, quien fue oficial de carabineros y encomendada a crear la escuela femenina de la DINA. Nancy Guzmán (2014) destaca que Olderock fue reconocida por la creación de torturas sexuales a partir de la utilización de animales, una práctica que la exagente realizaba en el centro de detención "La Venda Sexy":

A mí me tocó ser violada así, con ese animal, por eso te lo puedo decir. Es una de las historias más terribles y dolorosas que yo sólo he podido enfrentar hace muy pocos años. (Holszaphel, 2013)

Históricamente, tradicionalmente, las mujeres han sido botines de guerra y creo que esta no es la excepción. Tanto los torturadores, los guardias, pensaban que tenían poder ... pero con el poder que ellos tenían podían hacer lo que querían. Ahora, había mujeres muy aberrantes también, como la mujer dueña del perro...del Volodia. (Entrevista a Guillén, septiembre 2017)

Estas mujeres fueron capaces de articular esa narrativa dolorosa, generando un potencial de instigar a la acción, "producir formas de respuesta y reacción que suponen agencia" (Apparudai, 2001). En este sentido, la memoria reactivada socialmente gestó comunidades unidas en el "sentimiento de la sororidad", como diría bell hooks, "la sororidad es tu arma más poderosa ... no solo la hermandad femenina es necesaria y benéfica, sino que quizá sea una de las mayores herramientas transformadoras para toda la sociedad" (hooks, 2017, p. 38-40). Esta sororidad fue generando un escenario para un nuevo quehacer político. En este punto, vale la pena hacer notar el énfasis en la recuperación de memorias colectivas, no institucionales, sino aquellas almacenadas en la privacidad de una colectividad vejada. De este modo, estas memorias pudieron forjar puntos de encuentro, pulsaciones colectivas que están siendo consignadas en el ámbito político, ya que son

11 Manuel Contreras (creador y director de la DINA) llamó a Ingrid Olderock en octubre de 1973 para que formase una brigada femenina de la DINA, con 70 integrantes. Olderock se transforma en el agente represor más cruel, creando el centro de tortura Venda Sexy, donde desaparecieron al menos 27 personas...En ese centro clandestino pone en práctica la tortura a través de perros que ella misma entrenaba para que violasen a hombres y mujeres, señala Nancy Guzmán, autora del libro Sobre Ingrid Olderock, la mujer de los perros. 
especialmente aquellas experiencias innarrables, las que necesitan narrarse para que se produzca un cambio social:

Un segundo elemento para mí muy importante es que yo conocí el feminismo, lo que hoy día lo llamamos feminismo ... algo demostró en el sentido de que todos estos dolores y estos sufrimientos estaban muy permeados a los estereotipos que demostramos las mujeres, la vergüenza, la culpa, etc. Entonces como que noté en mi cuerpo también, que mucho de las cosas que sentía, las tenía que sentir en las cárceles como el estereotipo femenino. Y fue para mí una tremenda liberación para mí entender eso y salirme de eso. Después yo me hice mucho más feminista digamos, pero en ese minuto para entender eso, fue realmente una posibilidad de construir mi sanación también. (Entrevista a Bataszew, julio del 2017)

Como señala Scott, estas experiencias dolorosas y atroces forjaron la infrapolítica entre las compañeras detenidas y torturadas. Scott plantea que los grupos subordinados producen, a partir de su sufrimiento y a espaldas del dominador, un "discurso oculto" que representa una crítica del poder. Estas luchas discursivas son las que dan lugar a la creación de identidades basadas en la dignidad y en la autonomía entre los subordinados ${ }^{12}$. Es decir, la infrapolítica, hace posible ubicar en el discurso oculto "la vida política de los subordinados" (Scott, 2000, p. 21). Y es precisamente, aquí, donde se da la resistencia a la dominación y es, gracias a este discurso -en el caso de algunas mujeres que sufrieron la tortura-, que hoy estén forjando nuevas luchas políticas, como, por ejemplo, la instalación de la Ley de violencia política sexual:

Queríamos decir que la utilización de un poder sexualizado sobre las mujeres era una expresión política del terrorismo de Estado hacia las mujeres que luchaban, entonces ahí salió el concepto del enunciado de la violencia política sexual. Nosotras lo planteamos por varias razones: la primera era porque en la sociedad patriarcal y en nuestro sistema judicial heteronormativo no se diferencia la tortura de la violencia política sexual, por ende, la violencia político sexual queda absolutamente oculta ... no hay ni siquiera una condena de un día por violación o cualquier otro abuso que se haya cometido contra las mujeres en los tiempos de la dictadura militar. Estoy hablando de violación, de utilización de animales amaestrados, estoy hablando de electricidad en nuestros genitales, estoy hablando de embarazo forzado, estoy hablando de aborto forzado, etc. La mayoría de esas mujeres no hemos recibido ningún tipo de justicia. Entonces acuñamos este concepto inicialmente como una trasgresión

12 La propuesta de Scott es que integrando los discursos ocultos como formas de resistencia de los sujetos desposeídos se puede comprender la complejidad de la esfera política. Esa resistencia se manifiesta en formas encubiertas del lenguaje y de la acción, que se puede expresar en el rumor, el chisme o las bromas, como lo hicieron las mujeres en las casas de tortura. 
a la identidad corporal y sexual de las mujeres con un sentido claramente político contrainsurgente para impedir o castigar a las mujeres que luchan por sus derechos o contra las opresiones, y lo hicimos muy relacionado al artículo $7 \mathrm{G}^{13}$ del estatuto de Roma. (Entrevista a Bataszew, julio del 2017)

Hay que señalar que la primera querella por tortura sexual en Chile fue presentada por Patricia Herrera el año 2010 14 . En esa ocasión sostuvo: "no sólo es conmigo, es con las mujeres que pasaron las torturas y que hoy son detenidas desaparecidas, por lo que para mí es un compromiso de por vida" (Herrera, citada en Hiner, 2015, p. 867). El año 2014, Nieves Ayress, Alejandra Holszapfel, Soledad Castillo, Nora Brito y Beatriz Bataszew presentaron otra querella, esta vez por violencia política sexual, que fue acogida por tribunales ${ }^{15}$. Esta querella colocó en el tapete un aspecto de la represión que ha sido eludido, como es la violencia sexual y de género, que fue llevada a cabo de manera sistemática en contra de las personas prisioneras de recintos especializados en torturas sexuales, como lo fue la "Venda Sexy".

Y el año 2016, Beatriz Bataszew presentó otra querella por el mismo delito:

Junto a mis compañeras del Colectivo de Mujeres Sobrevivientes Siempre Resistentes, de las Feministas Autoconvocadas y de la Corporación Humanas, presenté una querella contra el estado chileno por violencia política sexual o tortura sexual. Esta es mi segunda querella, la primera, presentada hace 12 años fue sobreseída, es decir no hubo sentencia ni condenados. Lo anterior me llevó a confirmar algo que pensé prontamente una vez establecidos los gobiernos post dictadura, que se resume en nuestra consigna iiiNO HAY JUSTICIA, NO HAY VERDAD, iiiSOLAMENTE IMPUNIDAD!!! (BATASZEW, 2016)

Como mencionamos, las querellas a la justicia chilena comenzaron el año 2010. Primero tipificadas como "tortura sexual" y más tarde como "violencia política sexual"; sin embargo, estas formas de violencia y tortura ya habían sido declaradas en diferentes informes a fines de los años 80:

13 El Estatuto de Roma de la Corte Penal Internacional sostiene en El Artículo 7, que se entenderá por "crimen de lesa humanidad" cualquiera de los actos siguientes cuando se cometa como parte de un ataque generalizado o sistemático contra una población civil y con conocimiento de dicho ataque. La Letra G, de dicho artículo sostiene: g) Violación, esclavitud sexual, prostitución forzada, embarazo forzado, esterilización forzada o cualquier otra forma de violencia sexual de gravedad comparable.

14 "Presentan querella por violencia sexual como tortura en dictadura". Radio Bío-Bío, 7 de diciembre de 2010.

15 Santiago, de Chile, 16 de mayo 2014. (CODEPU). Exprisioneras políticas, sobrevivientes de los recintos de tortura de la dictadura, interpusieron la primera querella por violencia sexual patrocinada por la Corporación Parque por la Paz Villa Grimaldi. "Mujeres presentan querella por violencia sexual en contra de militares y policías que operaron como sicarios durante la dictadura". 
Cuando revisé las declaraciones que hice en la Vicaría de la Solidaridad donde hablábamos de la violencia política sexual, en esos tiempos no le colocábamos este nombre, pero sí describíamos lo que nos había pasado. Y solamente aparecía como trato humillante y se borraba el conjunto de texto, o sea, aparecía un rótulo trato humillante. Y lo demás estaba absolutamente borrado, nadie quería escuchar eso, pero, además, de que nadie lo quería escuchar, para el sistema heteronormativo esto es parte de la tortura, es un daño colateral de la tortura. Es una cosita poca que les pasa a las mujeres. Cuando nosotras sabemos que no es una cosita poca, es algo muy grave, muy tremendo para nosotras... a diferencia de los hombres que también lo fueron, pero en mucho menor medida. (Entrevista a Bataszew, julio del 2017)

Según Jelin (2001), los testimonios orales, realizados en ámbitos públicos, transcritos para "materializar la prueba", se enmarcan -se supone- en una expectativa de justicia y de cambio político. Si bien el testimonio en esos ámbitos puede tener como efecto el empoderamiento y legitimación de la voz de la sobreviviente, su función testimonial está centrada en la descripción fáctica, hecha con la mayor precisión posible, de la materialidad de la tortura y la violencia política. Se cree que cuanto menor emocionalidad e involucramiento del sujeto que narra, mejor, porque el testimonio oral tiene que reemplazar las "huellas materiales" del crimen. A la hora de narrar y relatar, según Elizabeth Jelin, las mujeres expresan más sentimientos, haciendo más referencias a lo íntimo y a las relaciones personalizadas, a sus miedos y a sus sentimientos de inseguridad (Jelin, 2001, p. 34).

\section{El género en las memorias}

Elizabeth Jelin (2001) se pregunta: ¿Hay algo más para decir sobre género y represión? ¿O sobre género y memoria? La autora señala que la represión tiene género, vale decir, que el impacto de la represión de las dictaduras en América Latina fueron diferentes en hombres y mujeres. Esto es explicable por sus posiciones diferenciadas en el sistema de género, posiciones que implican experiencias vitales y relaciones sociales jerárquicas claramente distintas (Jelin, 2001, p. 2). Además, la autora indica que "todos los informes existentes sobre la tortura señalan que el cuerpo femenino siempre fue un objeto especial para los torturadores" (Jelin, 2001, p. 4). Desde este ángulo, los análisis de Bunster Burroto, Tylor y Holander (citados en Molyneaux, 2003) se han procupado sobre hasta qué punto el género impregnaba el aparato y repertorio del terror, desplegado por los militares. De esta forma, el extendido uso de la tortura contra los sujetos prisioneros se erotizó y sexualizó. Las mujeres fueron sometidas rutinariamente a violaciones y otros abusos sexuales que expresaban una misoginia sádica (Molyneaux, 2003). El tratamiento de las mujeres incluía siempre una alta dosis de violencia sexual (Molyneaux, 2003). Hay 
que recordar, también, que muchas mujeres detenidas eran jóvenes y atractivas y, en consecuencia, más vulnerables al hostigamiento sexual (Jelin, 2001, p. 5).

El 95\% de las mujeres se le aplicó algún método de tortura, que se inscribe como violencia político sexual. Es decir, se la desnudó se la violó, se le abusó con animales, se le colocó electricidad en los senos, en la vagina, etc. El embarazo forzado. Hubo mujeres que resultaron embarazadas de sus torturadores. Hubo muchas mujeres que ni siquiera lo sabemos, porque en esos tiempos era complejo, que a lo mejor abortamos cuando estábamos embarazadas cuando se nos torturó, etc.... El cuerpo de las mujeres termina siendo un territorio al cual conquistar y dominar y se conquista y se domina bajo un poder sexualizado. Estos son crímenes de género, van direccionados hacia las mujeres y son realmente pensados. (Entrevista a Bataszew, julio del 2017)

Me llevaron primero a la Villa Grimaldi y lo primero que pasa es vejarte como mujer, sáquese la ropa, desnúdese, si a ver si anda con algún audífono micrófono por las orejas, por las narices, por la boca, por el ano o por la vagina y te revisan por todos lados y cuando a una mujer la desnudan en esa situación también te sientes terriblemente vulnerada, vejada, te hacen sentir como que si no vales nada ... luego comenzaron los interrogatorios, los parrillasos, corriente eléctrica...violación del guatón Romo. (Entrevista a Holszaphel, agosto 2017)

Según Jelin (2001), la polarización entre lo masculino/femenino, atractivo/pasivo, estaba naturalizada entre los militares. La experiencia de la violencia política y los tratamientos que se les dieron a hombres y mujeres en las salas de tortura no fue la misma para ambos sexos y esa diferencia en las vivencias se plasma en las variantes de composición formal y temática que presentan las memorias narradas.

Jelin señala que la experiencia directa y la intuición indican que mujeres y hombres desarrollan habilidades diferentes en lo que concierne a la memoria, en la medida en que la socialización de género implica prestar más atención a ciertos campos sociales y culturales que a otros y definir las identidades ancladas en ciertas actividades más que en otras. Existen algunas evidencias cualitativas que indican que las mujeres tienden a recordar eventos con más detalles, mientras que los varones tienden a ser más sintéticos en sus narrativas, o que las mujeres expresan sentimientos mientras que los hombres relatan más a menudo en una lógica racional y política (Jelin, 2001, p. 34). De esta manera, las mujeres hacen más referencias a lo íntimo y a las relaciones personalizadas, a sus miedos y a sus sentimientos de inseguridad (Leydesdorff, Passerim y Thompson, 1996, citados en Jelin, 2001). 
Por su parte, Michael Pollak (2006), quien trabaja una serie de testimonios de mujeres sobrevivientes del campo de concentración en Auschwitz, plantea:

[Se] presta especial atención a los hechos relatados, a la posición de las narradoras y a sus vínculos con los destinatarios, así como también a las formas elegidas para dar cuenta de la experiencia. Para Pollak, todos estos elementos moldean no sólo las formas que asumen los relatos, sino también las estructuras sobre las que se asienta la memoria como factor que posibilita la narración de esas experiencias extremas. (Pollak, 2006 citado en Daona, 2013, p. 58)

El trabajo de Pollak (1990) resulta significativo para reflexionar sobre cómo las mujeres narran sus testimonios y las relaciones que establecen con su entorno:

Uno llegaba, la primera pieza era la pieza de tortura, corriente eléctrica, violaciones, todo eso. En esa pieza, estaban los de investigaciones, después había otra pieza grande, donde estaba ese militar, que me viola ... y tengo súper claro que era él, era más bajo que yo, le pude ver claramente la cara, no lo olvidé nunca más, puedo fehacientemente decir que fue él. (Entrevista a Holszaphel, agosto, 2017)

\section{El ojo de la memoria}

Entre la memoria voluntaria e involuntaria, un olor, una música, te puede trasladar al pasado, una memoria que se doblega a la llamada de atención, "y así ocurre con nuestro pasado. En vano buscaremos conjugarlo a nuestra voluntad" (Proust, 1917, p. 69).

En la Venda Sexy, todos estábamos vendados. Cuando uno tiene una venda, cuando uno no puede ver o no escucha parece que se le agudizan los otros sentidos, así que escuchaba bien lo que hablaban ellos y...también reconocí los olores al llegar nuevamente a esa casa. (Entrevista a Guillén, septiembre 2017)

El ojo blanco vaciado de historia se debe llenar de una nueva, para poder ver con otra mirada. Nuestras sobrevivientes abren un espacio entre atrapar el pasado -no olvidar- y el futuro, espacio en blanco que hay que recuperar. Para Lacan, que utilizó el concepto de detener el ojo en su análisis de la mirada, "ese es el momento de la pulsación temporal” (Lacan, 1973), que llama al sujeto a hablar en tanto que sujeto. Y Lyotrad, por su parte, retoma el ritmo del tiempo de la enunciación, cuando discute el relato de la tradición "en el caso de las tradiciones populares... nada es acumulado, en el sentido de que los relatos deben ser repetidos todo el tiempo, porque estos son todo tiempo olvidados. Pero esto que no es publicado, es el ritmo temporal que no se detiene en enviar los relatos al olvido" (Lyotard 
y Thebaud, 1979). Es a través de este proceso del olvido -estar obligado a olvidar- que la identificación problemática de un pueblo nacional se vuelve visible. Como señala Bhabha, "estar 'obligado a olvidar', en la construcción del presente nacional, no es sólo una cuestión de memoria histórica, sino la construcción de un discurso sobre la sociedad que lleva a cabo el problema de totalizar al pueblo y de unificar la voluntad nacional" (Bhabha, 2007, p. 353).

Para prevenir el olvido, el discurso se orienta a fijar la memoria, resistiendo así a la versión histórica. "La historia es historia de la Nación", acota Ricoeur (2010) en su relectura de Halbwachs: "Repensarla, discutirla o 'polemizar' con ella, es alterar el orden canónico del discurso oficial, meterse con el rastrillo de la lectura-escritura en las grietas abiertas de la memoria, aún posibles de abrir, para cuestionar, poner en duda y enunciar de nuevo, mostrando los reveses de lo que aparece como verdadero e irrefutable" (Ricoeur, 2010, p. 508).

\section{Conclusiones}

La Venda, que implicó la inmovilidad del ojo, hace volver la mirada al pasado, desde donde hablan nuestras sobrevivientes, desde una identificación liberadora y no reprimida, que suscita precisamente una crisis en la representación del sujeto y que posibilita la subversión política.

La memoria narrativa, de mujeres que sufrieron la tortura de forma sistemática, que en un primer momento operó desde una "condición traumática", más tarde pasó a ser parte de todo un proceso de resignificación, a través de la verbalización de sus vivencias, pudiendo vencer la memoria del terror y del miedo. El proceso de mitigar el trauma de la tortura, que en la mayoría de las mujeres que pasaron por la Venda Sexy fue la violación, tuvo que arrancar la palabra del útero y provocar un desgarramiento, una hemorragia identitaria, para enfrentar ese cuerpo ultrajado, y abrirlo y mostrarlo con subversión.

Estas mujeres fueron capaces de articular esa narrativa dolorosa, generando un potencial de instigar a la acción, unidas en la sororidad, pudiendo forjar puntos de encuentro, pulsaciones colectivas que están siendo consignadas en el ámbito político, participando activamente en movimientos colectivos de lucha, como lo es el colectivo de "Mujeres sobrevivientes, siempre resistentes". 


\section{Bibliografía}

Apparudai, A. (2001). La modernidad desbordada. Dimensiones culturales de la globalización. Buenos Aires: Fondo de Cultura Económica.

Arellano, C. (2014). Poéticas del cuerpo: Flujos y fluctuaciones: Una mirada al desmontaje del cuerpo a través de la poesía del Sur de Chile. Revista Nomadías, 20, 11-26. doi: 10.5354/0719. 0905.2016.39133 Santiago, Universidad de Chile Disponible en https://nomadias.uchile.cl/ index.php/NO/article/view/39133

Arellano, C. (2017). ¿Cómo se borda la poética del abandono? Revista Internacional de Culturas y Literaturas, 20, 7-22, 2017. doi: 10.12795/RICL http://hdl.handle.net/11441/62776 Acceso el 22/03/2018 Universidad de Sevilla, España. Disponible en https://idus.us.es/xmlui/ handle/11441/62776

Arendt, H. (2006). Los orígenes del totalitarismo. España: Alianza Editorial.

Barahona de Brito, A., González, Carmen y Aguilar, Paloma. (Eds). (2001). The Politics of Memory and Democratization. Oxford: University Press.Bataszew, Beatriz. (06 de diciembre, 2016). Querella contra el Estado chileno por violencia política sexual o tortura sexual. Werkenrojo. Disponible en http://werkenrojo.cl/tag/violencia-politica-sexual/

Bhabha, H. (2007). Les Lieux de la Culture. Une Théorie Postcoloniale. Paris : Editions Payot

Corradi, J., Weiss, Patricia; Garretón, Manuel Antonio. (1992). Fear at the edge. State Terror and Resistance in Latin America. En University of California Press [online] 104-118, 1992. Disponible en https://www.ucpress.edu/book/9780520077058/fear-at-the-edge ISBN: 9780520077058 Acceso el 28/03/2018

Chornik, K. (2019). Violencia sexual, tortura y memoria histórica en Chile. En Open Democracy [online] https://www.opendemocracy.net/es/democraciaabierta-es/the-sale-of-the-venda-sexy-detention-centre-highlights-chiles-struggle-for-historical-memory-and-against-pinochets-legacy-of-sexual-violence/

Daona, V. (2013). Mujeres, escritura y terrorismo de Estado en Argentina: Una serie de relatos testimoniales. En Moderna språk, 2 [online]. Disponible en http://ojs.ub.gu.se/ojs/index. php/modernasprak/article/viewFile/2654/2411

Delgado, Felipe. (7 de diciembre de 2010). Presentan querella por violencia sexual como tortura en dictadura. Radio Bío-Bío. Disponible en http://www.biobiochile.cl/2010/12/07/presentan-querella-por-violencia-sexual-como-tortura-en-dictadura.shtml

The Clinic, Archivo Memoriaviva. (11 de septiembre 2013). Alejandra Holzapfel: Yo sobreviví a Venda Sexy. Disponible en http://www.memoriaviva.com/criminales/criminales_o/ olderock_ingrid.htm 
Edkins, J. (2003). Trauma and the memory of politics. En Cambridge University Press. [online]. Disponible en https:/ /www.cambridge.org/core/books/trauma-and-the-memory-of-politics/ 78FB69F2E8FC138EBDDA13691B69B3FA https://doi.org/10.1017/CBO9780511840470 Acceso el 20/04/2018

EPES, Fundación de Educación Popular en Salud. (17 mayo, 2014). Mujeres presentan querella por violencia sexual en contra de militares y policías que operaron como sicarios durante la dictadura. Disponible en http://www.epes.cl/2014/05/mujeres-presentan-querella-por-violencia-sexual-en-contra-de-militares-y-policias-que-operaron-como-sicarios-durante-la-dictadura/

Franco, J. (1992). Gender, Death and Resistance: Facing the Ethical Vacuum. En Corradi, J., Weiss Fagen, P., Garretón, M. (Ed.), Fear at the edge. State Terror and Resistance in Latin America (pp. 104-118). California: University of California Press.

Guzmán, N. (2014). Ingrid Olderock. La mujer de los perros. Santiago de Chile: Ceibo Ediciones.

Halbwachs, M. (2011). La memoria colectiva. España, Miño y Dávila Editores

Hiner, H. 2015. Fue bonita la solidaridad entre mujeres: Género, resistencia, y prisión política en Chile durante la dictadura. Revista Estudos Feministas 23(3), 867-892. Disponible en http:// www.scielo.br/scielo.php?script=sci_arttext\&pid=S0104-026X2015000300867\&lng=es\& $t$ th$\mathrm{g}=$ es http://dx.doi.org/10.1590/0104-026X2015v23n3p867 Acceso el 20/05/2018

Hooks, B. (2000). El feminismo es para todo el mundo (Trad. Beatriz Esteban, Lina Lozano, Mayra Moreno, Maira Puertas y Sara Vega). Madrid: Traficantes de Sueños. Disponible en https:// www.traficantes.net/sites/default/files/pdfs/TDS_map47_hooks_web.pdf

Informe Valech. (2005). Comisión Nacional sobre Prisión Política y Tortura. Capitulo VII, 2. Disponible en http://www.memoriachilena.gob.cl/602/w3-article-85804.html

Janet, P. (2006). L'evolution de la memoire et de la notion du temps. Paris: Editions L'Harmatan.

Jelin, E. (1994). iAnte, de, en, y? Mujeres y derechos humanos. América Latina Hoy, 9, 7-23. Salamanca, España, Universidad de Salamanca. Disponible en https://dialnet.unirioja.es/ servlet/articulo?codigo $=1971753$

Jelin, E. (2001). Los trabajos de la memoria. España: Siglo Veintiuno Editores.

Lacan, J. (1973). Aliénation, in Les Quatre Concepts fondamentaux de la psychanalyse. Paris: Seuil.

Lyotard, J. et Jean Loup Thebaud. (1979). Au juste. Paris: Bourgois.

Molyneux, M. (2003). Movimientos de mujeres en América Latina: Estudio teórico comparado. España, Madrid: Cátedra. Disponible en https://dialnet.unirioja.es/servlet/libro?codigo=159737 Acceso el 11/10/2019 
Nikken, P. (1994). El concepto de derechos humanos. En Estudios Básicos de Derechos Humanos. San José, Venezuela: Instituto Interamericana de Derechos Humanos IIDH. Disponible en https://www.civilisac.org/civilis/wp-content/uploads/El-concepto-de-derechos-humanos-Pedro-Nikken.pdf Acceso el 21/08/2017

ONU. (1998). Estatuto de Roma de la Corte Penal Internacional. Disponible en http://www.oas. org/36ag/espanol/doc_referencia/Estatuto_Roma.pdf

Pino-Ojeda, W. (2011). Noche y niebla: Neoliberalismo, memoria y trauma en el Chile postautoritario. Santiago de Chile: Editorial Cuarto Propio.

Proust, M. (1917). A la recherche du temps perdu (Vol I). Du côté de chez Swuann, Paris: Gallimard.

Ricoeur, P. (2010). La memoria, la historia, el olvido. México: F.C. E.

Richard, N. (2001). Las marcas del destrozo y su reconfiguración en plural. Pensar en/la postdictadura (Eds. Nelly Richard y Alberto Moreiras). Santiago: Editorial Cuarto Propio

Salazar, G. (2001). Memoria social y movimiento popular: Pasado y proyección. En OLEA, Raquel y GRAU, Olga (Comps.), Volver a la memoria. Santiago: LOM/La Morada Ediciones

Scott, J. (2000). Los dominados y el arte de la resistencia. Discursos ocultos. México: Ediciones Era

Taramasco, F. (2003). Indiferencia y evitación como significados de la omisión. Castalia, Revista de Psicología de la Academia, 04. Disponible en http://bibliotecadigital.academia.cl/ handle/123456789/2398

Valdés, H. (1974). Tejas verdes. Diario de un campo de concentración en Chile. Disponible en www. memoriachilena.cl 